\title{
Hospital volume, mitral repair rates, and mortality in mitral valve surgery in the elderly: An analysis of US hospitals treating Medicare fee-for-service patients
}

\author{
Christina M. Vassileva, MD, ${ }^{\mathrm{a}}$ Christian McNeely, BS, ${ }^{\mathrm{a}}$ John Spertus, MD, ${ }^{\mathrm{b}}$ Stephen Markwell, MA, ${ }^{\mathrm{a}}$ and \\ Stephen Hazelrigg, $\mathrm{MD}^{\mathrm{a}}$
}

\begin{abstract}
Background: The volume-outcome relationship has been suggested as a quality metric in mitral valve surgery and would be particularly relevant in the elderly because of their greater burden of comorbidities and higher perioperative risk.

Methods and Results: The study included 1239 hospitals performing mitral valve surgery on Medicare beneficiaries from 2000 through 2009. Only 9\% of hospitals performed more than 40 mitral operations per year, $29 \%$ performed 5 or less, and $51 \%$ performed 10 or less. Mitral repair rates were low; $22.7 \%$ of hospitals performed 1 or less, $65.1 \%$ performed 5 or less, and only $5.6 \%$ performed more than 20 mitral repairs per year in those aged 65 years or more. Repair rates increased with increasing volume of mitral operations per year: 5 or less, $30.5 \%$; 6 to $10,32.9 \% ; 11$ to $20,34.9 \% ; 21$ to $40,38.8 \%$; and more than $40,42.0 \%$ $(P=.0001)$. Hospitals with lower volume had significantly higher adjusted operative mortality compared with hospitals performing more than 40 cases per year: 5 or less cases per year, odds ratio (OR) 1.58 (95\% confidence interval [CI], 1.401.78 ); 6 to 10 cases per year, OR 1.29 (95\% CI, 1.17-1.43); 11 to 20 cases per year, OR 1.17 (95\% CI, 1.07-1.28); 21 to 40 cases per year, OR 1.15 (95\% CI, 1.05 1.26). Hospitals with lower mitral repair rates had an increased likelihood of operative mortality relative to the top quartile: lowest quartile, OR $1.31(95 \% \mathrm{CI}, 1.20$ 1.44); second quartile, OR 1.18 (95\% CI, 1.09-1.29); and third quartile, OR 1.14 (95\% CI, 1.05-1.24). Long-term mortality beyond 6 months was also higher in low-volume hospitals: 5 or less cases year, hazard ratio (HR) $1.11(95 \% \mathrm{CI}$, 1.06-1.18); 6 to 10 cases per year, OR 1.06 (95\% CI, 1.02-1.10) compared with hospitals performing more than 40 cases per year.
\end{abstract}

Conclusions: Most hospitals perform few mitral valve operations on elderly patients. Greater volume of mitral procedures was associated with higher repair rates. Both greater volume of mitral procedures and increasing mitral repair rates were associated with decreased mortality. (J Thorac Cardiovasc Surg 2015;149:762-8)

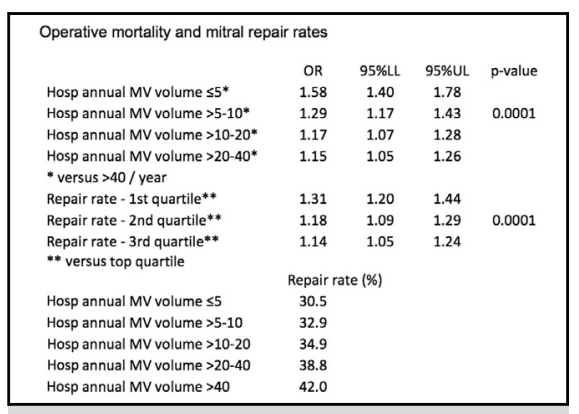

Odds ratios for adjusted operative mortality along with mitral valve repair rates.

\section{Central Message}

The majority of hospitals perform few mitral valve operations. Greater mitral procedural volume was associated with lower adjusted mortality, higher long-term survival, and higher repair rates. Lower hospital mitral repair rates were also independently predictive of higher mortality.

\section{Author Perspective}

Prior studies have found a relationship between volume and outcomes in cardiac surgery. We found that valve repair rates and mortality vary by hospital annual mitral procedure volume and that the majority of hospitals have a limited experience in treating elderly patients with mitral valve disease. We found a significant increase in mitral repair rates and a decrease in mortality as a function of hospital annual mitral procedure volume. Our findings support and extend prior reports suggesting that instituting specific volume thresholds for hospitals wishing to perform mitral valve surgery may lead to improved surgical outcomes.

See Editorial Commentary pages 769-70.
From the Division of Cardiothoracic Surgery, ${ }^{\mathrm{a}}$ Department of Surgery, Southern Illinois University School of Medicine, Springfield, Ill; and Saint Luke's Mid America Heart Institute, ${ }^{b}$ University of Missouri - Kansas City, Kansas City, Mo. Received for publication April 8, 2014; revisions received Aug 27, 2014; accepted for publication Aug 31, 2014; available ahead of print Oct 24, 2014

Address for reprints: Christina M. Vassileva, MD, Division of Cardiothoracic Surgery, Southern Illinois University School of Medicine, $701 \mathrm{~N}$ First St, PO Box 19638, Springfield, IL 62794-9638 (E-mail: cvassileva@ siumed.edu). 0022-5223/\$36.00

Copyright (C) 2015 by The American Association for Thoracic Surgery http://dx.doi.org/10.1016/j.jtcvs.2014.08.084
The management of elderly patients with mitral valve disease is complex. Options include medical management of heart failure symptoms and surgical intervention, consisting of either mitral repair or replacement. We recently found that outcomes after mitral surgery in the Medicare population are much better than previously reported; survival for those who underwent repair was similar to the age- and gender-matched US population. ${ }^{1}$ Despite these favorable outcomes, mitral replacement is much more common in the elderly. ${ }^{2}$ Hospitals vary dramatically in the number of mitral valve operations performed.

Previous studies have investigated the relationship between volume and outcome in mitral valve surgery. ${ }^{3,4}$ Using data from the Society of Thoracic Surgeons (STS) database, Gammie and colleagues ${ }^{3}$ analyzed data from 


\section{Abbreviations and Acronyms \\ BASF $=$ Beneficiary Annual Summary Files \\ CI = confidence interval \\ CMS $=$ Centers for Medicare and Medicaid Services \\ HR = hazard ratio \\ MEDPAR $=$ Medicare Provider Analysis and Review \\ NIS = Nationwide Inpatient Sample \\ OR $=$ odds ratio \\ STS $=$ Society of Thoracic Surgeons}

575 participating hospitals from 2000 to 2003 and found that a higher volume of mitral procedures was associated with lower adjusted operative mortality and increased repair rates. ${ }^{3}$ Because the mean age of the patient population included in that report was lower than 65 years, it is unclear if these findings can be extrapolated to older patients. In addition, far fewer hospitals participated in the STS at that time and it is possible that participating hospitals differed from nonparticipating hospitals. A more representative analysis of contemporary treatment in the elderly is needed to support this previously reported volumeoutcome relationship.

Birkmeyer and colleagues ${ }^{4}$ used the Medicare database to examine the relationship between hospital volume and surgical mortality for a variety of procedures in the United States, including aortic and mitral valve replacement and found an inverse relationship. This methodology was limited by not taking into account the interhospital variability in the proportion of Medicare cases performed (ie, it was assumed that hospitals do not differ in the number of Medicare patients they see) as well as any variability of the proportion of Medicare cases performed at each hospital over time. Moreover, it did not include information on mitral repair, a procedure that has been used with increasing frequency in mitral valve surgery. The purpose of this investigation was to extend these previous efforts by providing a descriptive analysis of the association between hospital volume of mitral procedures, mitral valve repair rates, and mortality in the Medicare population.

\section{METHODS}

\section{Data Sources}

The data files used for the present study included the Medicare Provider Analysis and Review (MEDPAR) files and corresponding Beneficiary Annual Summary Files (BASF) from 1999 to 2009. The MEDPAR files contain institutional claims for inpatient services covered under Part A. The BASF files contain information on patient demographics, eligibility, enrollment, summarized service utilization and payment, and chronic condition flags for eligible beneficiaries. The Vital Status file for February 2012 was used to calculate long-term survival.

The study was approved by the Institutional Review Board of Southern Illinois University, which waived the requirement for informed consent. In addition, beneficiary confidentiality data was protected through a rigorous data use agreement with Centers for Medicare and Medicaid Services (CMS).

\section{Patient Cohort}

All Medicare beneficiaries aged 65 years or older who underwent mitral valve repair (International Classification of Diseases, Ninth Edition, Clinical Modification [ICD-9-CM] code 35.12) or replacement (35.23 or 35.24) from 2000 through 2009 were considered for inclusion. Figure 1 provides a flowchart outlining patient selection for the analysis. The ICD-9 codes used for the exclusions are provided in Table E1. Patients with significant concomitant procedures or other nonvalvular procedures were excluded to more directly assess the relationship between the volume of more straightforward mitral valve operations and outcomes. In addition, to ensure a more complete assessment of patient risk factors, patients were excluded if they did not have 12 months of Medicare Part A and Part B coverage in the year preceding their index admission, or if they had a period of enrollment under a Medicare managed plan at any point in the year before their index admission. Patients with emergency admission status were also excluded from the analysis.

\section{Data Variables}

The index admission was defined as the first hospitalization documenting a mitral valve repair or replacement during the 10 -year period from 2000 through 2009. Demographic and comorbidity data were obtained from the MEDPAR file, using ICD-9-CM diagnostic codes from both the index admission and any hospitalizations during the 12-month period before the index admission. Operative mortality was defined as hospital or 30-day mortality, whichever was longer, in accordance with the standard STS definition. Long-term mortality was calculated from the Vital Status file for February 2012. Hospital annual volume of mitral procedures was calculated as the average number of mitral valve operations per year, that is, the total number of mitral valve operations paid for by Medicare over the 10-year study period, divided by the number of years that the hospital reported performing mitral valve operations. Thus, if a hospital had claims only in 6 of the 10 years, the total number of claims would be divided by 6 . After examining the distribution of annual mitral valve volumes across hospitals, we identified clinically and statistically relevant categories of annual volumes. Similarly, the hospital annual volume of mitral repairs was defined as the average number of mitral valve repairs per year. The average annual mitral repair rates for each hospital were categorized into quartiles of the distribution across the hospitals.

\section{Statistical Analysis}

Categorical patient characteristics were compared across the volume groups using the $\chi^{2}$ test, including observed mitral repair rates. A Cochran-Armitage trend test was used to assess the influence of the volume of mitral procedures on mitral repair rates. In order to account for clustering of patients within hospitals, hierarchical logistic regression was used to model operative mortality. Adjusted odds ratios (ORs) are presented, accounting for the clustering of patients within hospitals, the hospital characteristics of annual volume of mitral valve procedures and mitral valve repair rates, as well as the baseline patient and surgery characteristics. Similarly, Cox proportional hazards models, specifying hospital as a random effect to account for patients being nested within hospitals, were used to examine the impact of patient and hospital characteristics on long-term mortality beyond 6 months. After inspecting mortality curves, we chose to look at the impact of these factors on long-term mortality after the initial 6-month period after surgery because there is a high mortality phase immediately after surgery followed by a fairly constant hazard of death thereafter. Adjusted hazard ratios (HRs) reflecting the relative increase/decrease in the likelihood of death over the follow-up period from more than 6 months to 10 years are presented. All analyses were performed using SAS v 9.3 (SAS Institute Inc, Cary, NC). 


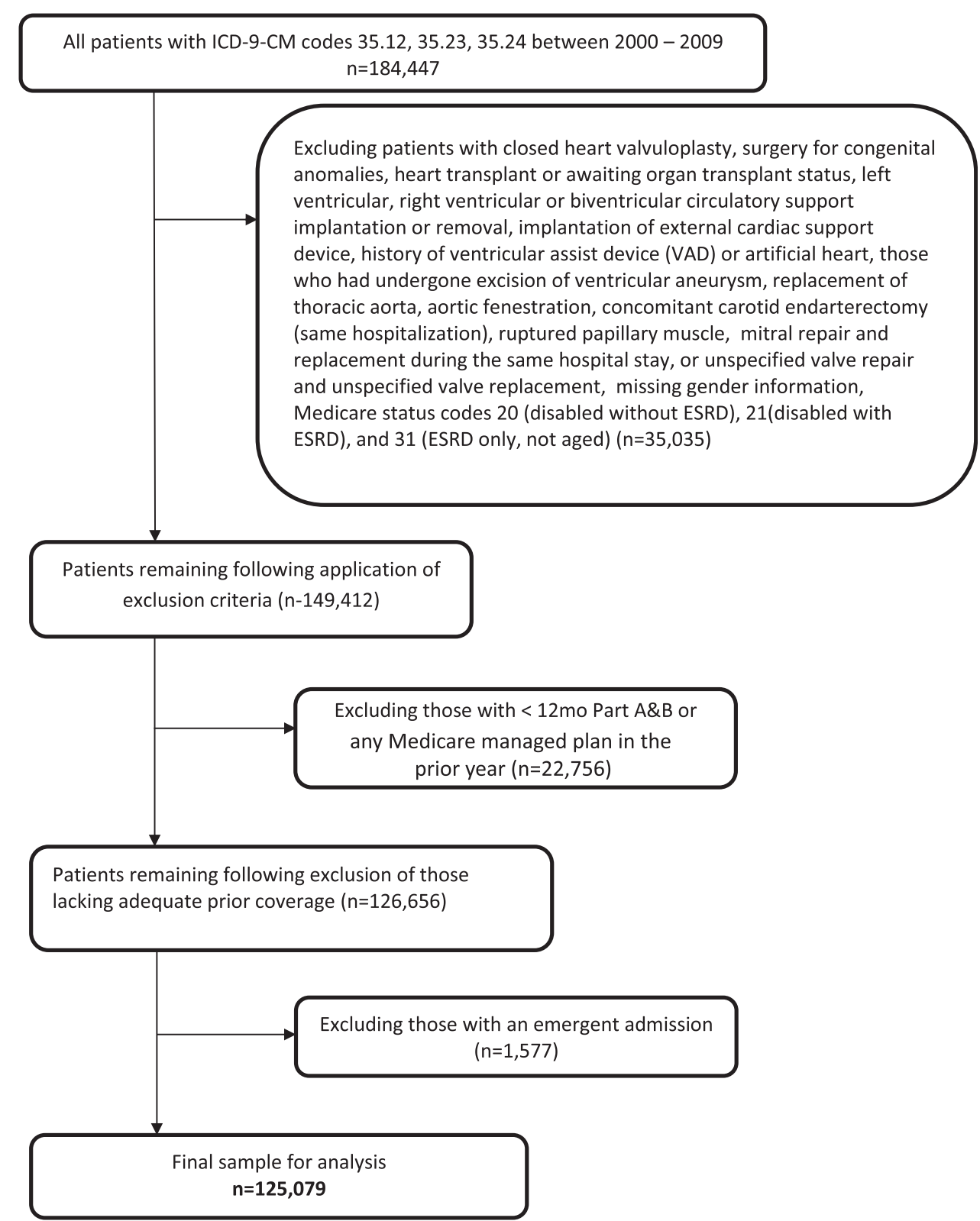

FIGURE 1. Flowchart of patient selection. ICD-9-CM, International Classification of Diseases, Ninth Edition, Clinical Modification; ESRD, end-stage renal disease; $V A D$, ventricular assist device.

TABLE 1. Distribution of annual hospital volumes of Medicare mitral procedure $(\mathbf{n}=\mathbf{1 2 3 9})$

\begin{tabular}{lcccccc}
\hline \multicolumn{2}{c}{ All mitral procedures } & & \multicolumn{3}{c}{ Mitral repairs } \\
\cline { 1 - 1 } \cline { 5 - 6 } Range & No. of hospitals & $\%$ & & Range & No. of hospitals & $\%$ \\
\hline & & & & 36 & 2.9 \\
$\leq 5$ & 354 & 28.6 & & 245 & 19.8 \\
$6-10$ & 276 & 22.3 & & $2-5$ & 525 & 42.4 \\
$11-20$ & 313 & 25.3 & $6-10$ & 233 & 18.8 \\
$21-40$ & 188 & 15.2 & & $11-20$ & 130 & 10.5 \\
$>40$ & 108 & 8.7 & & $>20$ & 70 & 5.6 \\
\hline
\end{tabular}

\section{RESULTS}

Distribution of Mitral Valve Operations

This study included all US hospitals using the Medicare fee-for-service system that performed any mitral operations on Medicare patients during the study period. A total of 1239 hospitals were included in the study. The number of mitral valve operations performed on Medicare patients at most of the hospitals was low (Table 1). More than one quarter $(28.6 \%)$ of the hospitals performed 5 mitral operations or less per year and $50.9 \%$ of the hospitals performed 10 or less mitral valve operations per year. In contrast, only 
TABLE 2. Baseline characteristics by hospital volume

\begin{tabular}{|c|c|c|c|c|c|c|c|}
\hline Characteristics & $\begin{array}{c}\text { Overall \% } \\
(\mathrm{n}=\mathbf{1 2 5 , 0 7 9 )}\end{array}$ & $\begin{array}{c}\% \leq 5 \\
(n=\mathbf{4 8 9 7})\end{array}$ & $\begin{array}{c}\%>5-10 \\
(n=11,765) \\
\end{array}$ & $\begin{array}{c}\%>10-20 \\
(n=27,618)\end{array}$ & $\begin{array}{c}\%>20-40 \\
(n=33,318)\end{array}$ & $\begin{array}{c}\%>40 \\
(n=47,481)\end{array}$ & $P$ value \\
\hline \multicolumn{8}{|l|}{ Patient characteristics } \\
\hline Age $\geq 75$ y & 55.6 & 51.4 & 54.1 & 55.6 & 56.6 & 55.8 & .0001 \\
\hline Female & 53.2 & 56.7 & 55.1 & 53.7 & 52.9 & 52.4 & .0001 \\
\hline Hypertension & 53.7 & 52.8 & 52.9 & 52.4 & 53.9 & 54.5 & .0001 \\
\hline Diabetes & 20.7 & 21.7 & 20.2 & 20.6 & 20.8 & 20.6 & .2791 \\
\hline PVD & 3.9 & 3.6 & 3.6 & 3.9 & 3.8 & 4.1 & .0615 \\
\hline Stroke & 9.7 & 9.7 & 9.5 & 9.8 & 9.6 & 9.9 & .7135 \\
\hline Heart failure & 63.8 & 65.9 & 64.0 & 62.9 & 64.2 & 63.7 & .0002 \\
\hline $\mathrm{CAD}$ & 59.1 & 57.0 & 59.0 & 58.7 & 59.6 & 59.1 & .0066 \\
\hline COPD & 20.7 & 22.9 & 23.0 & 20.8 & 20.2 & 20.2 & .0001 \\
\hline Respiratory failure & 12.8 & 16.9 & 14.8 & 13.9 & 12.8 & 11.4 & .0001 \\
\hline Renal failure & 11.0 & 24.6 & 24.1 & 23.6 & 24.2 & 22.5 & .0001 \\
\hline Atrial fibrillation & 46.8 & 44.3 & 45.0 & 45.0 & 46.8 & 48.5 & .0001 \\
\hline Anemia & 17.0 & 18.3 & 17.3 & 16.7 & 16.8 & 17.0 & .0606 \\
\hline History of MI & 19.8 & 19.0 & 19.6 & 19.8 & 20.1 & 19.7 & .3432 \\
\hline Previous cardiac surgery & 3.7 & 2.7 & 2.9 & 3.5 & 3.8 & 4.1 & .0001 \\
\hline \multicolumn{8}{|l|}{ Surgery characteristics } \\
\hline Urgent admission & 58.0 & 58.6 & 55.4 & 56.4 & 58.3 & 59.2 & .0001 \\
\hline Mitral valve repair & 38.3 & 30.5 & 32.9 & 34.9 & 38.8 & 42.0 & .0001 \\
\hline CABG & 46.8 & 46.8 & 48.4 & 48.3 & 47.8 & 44.9 & .0001 \\
\hline Other valve surgery & 24.5 & 17.9 & 18.5 & 23.1 & 25.2 & 27.0 & .0001 \\
\hline
\end{tabular}

$8.7 \%$ of the hospitals performed more than 40 mitral operations per year.

The annual hospital rate of mitral repairs ranged from $0 \%$ to $100 \%$. The median annual hospital repair rate was $32.9 \%$ (interquartile range [IQR], $21.8 \%$ to $44.4 \%$ ). The 10 th and 90th percentiles were $12 \%$ and $54 \%$, respectively. Furthermore, the distribution of mitral repair volumes among the hospitals revealed that almost one quarter of the hospitals $(22.7 \%)$ performed only 1 or no mitral repairs per year and that most hospitals $(65.1 \%)$ performed 5 or fewer mitral repairs per year. Only $5.6 \%$ of the hospitals performed more than 20 mitral repairs per year on Medicare patients.

\section{Patient Characteristics}

The study population included a total of 125,079 patients; $47,897(38.3 \%)$ underwent mitral valve repair and 77,182 $(61.7 \%)$ underwent mitral valve replacement. The median age was 75 years. The baseline characteristics for the overall cohort of patients undergoing mitral valve surgery as well as by hospital volume are presented in Table 2 . Higher-volume hospitals treated patients with a higher incidence of atrial fibrillation, a higher proportion of patients who required concomitant other valve surgery, and a higher percentage of reoperations (Table 2). Mitral repair rates increased significantly with increasing hospital annual volume of mitral procedures $(P=.0001)$, from $30.5 \%$ for hospitals performing 5 of fewer mitral operations per year to $42.0 \%$ for hospitals performing more than 40 mitral operations per year.

\section{Hospital Mortality}

The overall hospital mortality rate was $10.7 \%$. The results of the hierarchical logistic regression model for adjusted operative mortality are presented in Table 3. In this model, each hospital mitral volume category was used as a separate covariate. Similarly, mitral repair rates were divided into quartiles and each quartile was examined as an independent covariate. Because preoperative profiles differed among patients presenting to different volume centers, adjusted operative mortality was calculated to account for these differences. After adjustment for baseline characteristics and hospital repair rates (quartiles), the lowervolume hospitals all exhibited increased likelihood of operative mortality relative to those hospitals performing more than 40 cases per year: 5 or less cases per year, OR 1.58 (95\% confidence interval [CI], 1.40-1.78); 6 to 10 cases per year, OR 1.29 (95\% CI, 1.17-1.43); 11 to 20 cases per year, OR 1.17 (95\% CI, 1.07-1.28); 21 to 40 cases per year, OR 1.15 (95\% CI, 1.05-1.26).

When hospitals were divided into 4 quartiles according to their annual repair rates, the hospitals with the lowest annual repair rates also had an increased likelihood of operative mortality relative to those in the top quartile: lowest quartile, OR 1.31 (95\% CI, 1.20-1.44); second quartile, OR 1.18 (95\% CI, 1.09-1.29); and third quartile, OR 1.14 (95\% CI, 1.05-1.24). The median repair rates and the range for each quartile were as follows: first quartile, median $14 \%$, range $0 \%$ to $22 \%$; second quartile, median $28 \%$, range $22 \%$ to $33 \%$; third quartile, median $38 \%$, range $33 \%$ to $44 \%$; fourth quartile, median $52 \%$, range $44 \%$ to $100 \%$. 
TABLE 3. Operative mortality

\begin{tabular}{|c|c|c|c|c|}
\hline Characteristics & $\begin{array}{l}\text { Odds } \\
\text { ratio }\end{array}$ & $\begin{array}{c}\mathbf{9 5} \% \\
\text { Lower limit }\end{array}$ & $\begin{array}{c}95 \% \\
\text { Upper limit }\end{array}$ & $P$ valu \\
\hline Age $\geq 75 y$ & 1.60 & 1.53 & 1.66 & .0001 \\
\hline Female & 1.28 & 1.23 & 1.33 & .0001 \\
\hline Hypertension & 0.69 & 0.66 & 0.72 & .0001 \\
\hline Diabetes & 1.06 & 1.02 & 1.11 & .0092 \\
\hline PVD & 1.33 & 1.22 & 1.45 & .0001 \\
\hline Stroke & 1.66 & 1.57 & 1.75 & .0001 \\
\hline Heart failure & 1.33 & 1.27 & 1.39 & .0001 \\
\hline CAD & 0.83 & 0.79 & 0.87 & .0001 \\
\hline COPD & 1.12 & 1.07 & 1.17 & .0001 \\
\hline Respiratory failure & 2.49 & 2.39 & 2.61 & .0001 \\
\hline Renal failure & 1.78 & 1.69 & 1.88 & .0001 \\
\hline Atrial fibrillation & 0.76 & 0.73 & 0.79 & .0001 \\
\hline Anemia & 0.94 & 0.90 & 0.99 & .0189 \\
\hline History of MI & 1.44 & 1.38 & 1.51 & .0001 \\
\hline Previous cardiac surgery & 1.03 & 0.92 & 1.14 & .6557 \\
\hline Urgent admission & 1.76 & 1.68 & 1.85 & .0001 \\
\hline CABG & 1.37 & 1.31 & 1.44 & .0001 \\
\hline Other valve surgery & 1.61 & 1.55 & 1.68 & .0001 \\
\hline \multicolumn{5}{|c|}{$\begin{array}{l}\text { Hospital annual volume of } \\
\text { mitral valve procedures }\end{array}$} \\
\hline$\leq 5^{*}$ & 1.58 & 1.40 & 1.78 & \\
\hline $6-10 *$ & 1.29 & 1.17 & 1.43 & .0001 \\
\hline $11-20^{*}$ & 1.17 & 1.07 & 1.28 & \\
\hline $21-40 *$ & 1.15 & 1.05 & 1.26 & \\
\hline \multicolumn{5}{|l|}{ Repair rate } \\
\hline First quartile** & 1.31 & 1.20 & 1.44 & \\
\hline Second quartile** & 1.18 & 1.09 & 1.29 & .0001 \\
\hline Third quartile** & 1.14 & 1.05 & 1.24 & \\
\hline
\end{tabular}

$P V D$, Peripheral vascular disease; $C A D$, coronary artery disease; $C O P D$, chronic obstructive pulmonary disease; $M I$, myocardial infarction; $C A B G$, coronary artery bypass graft. *Versus $>40$ per year. **Versus top quartile.

Important surgical characteristics that were associated with increased operative mortality included urgent admission status and concomitant coronary artery bypass graft (CABG) or other valve surgery. Important patient baseline characteristics that were predictive of increased operative mortality included respiratory failure, stroke, renal failure, history of previous myocardial infarction and age 75 years or more.

\section{Long-Term Mortality}

The overall long-term mortality rates were $20.1 \%$ at 1 year, $29.0 \%$ at 3 years, $39.0 \%$ at 5 years, and $66.4 \%$ at 10 years. The 6 -month mortality rates for the volume groups were $21.5 \%$ for patients in the hospitals with the lowest volume ( $\leq 5$ cases per year), $19.3 \%$ for those in the hospitals with 6 to 10 cases per year, $17.7 \%$ for those in the hospitals with 11 to 20 cases per year, $17.5 \%$ for those in the hospitals with 21 to 40 cases per year, and $15.4 \%$ for those in hospitals with more than 40 cases per year. After adjustment for baseline characteristics and hospital repair rates (quartiles), patients in the lower-volume hospitals exhibited greater long-term mortality beyond 6 months relative to those
TABLE 4. Long-term mortality

\begin{tabular}{|c|c|c|c|c|}
\hline Characteristics & $\begin{array}{c}\text { Hazard } \\
\text { ratio }\end{array}$ & $\begin{array}{c}95 \% \\
\text { Lower limit }\end{array}$ & $\begin{array}{c}95 \% \\
\text { Upper limit }\end{array}$ & $P$ value \\
\hline Age $\geq 75 y$ & 1.54 & 1.51 & 1.57 & .0001 \\
\hline Female & 0.96 & 0.94 & 0.98 & .0001 \\
\hline Hypertension & 0.94 & 0.92 & 0.96 & .0001 \\
\hline Diabetes & 1.37 & 1.34 & 1.40 & .0001 \\
\hline PVD & 1.20 & 1.15 & 1.26 & .0001 \\
\hline Stroke & 1.24 & 1.20 & 1.28 & .0001 \\
\hline Heart failure & 1.40 & 1.37 & 1.43 & .0001 \\
\hline $\mathrm{CAD}$ & 1.06 & 1.04 & 1.09 & .0001 \\
\hline COPD & 1.52 & 1.48 & 1.55 & .0001 \\
\hline Respiratory failure & 1.26 & 1.23 & 1.30 & .0001 \\
\hline Renal failure & 1.78 & 1.72 & 1.83 & .0001 \\
\hline Atrial fibrillation & 1.09 & 1.07 & 1.12 & .0001 \\
\hline Anemia & 1.13 & 1.10 & 1.16 & .0001 \\
\hline History of MI & 1.11 & 1.08 & 1.14 & .0001 \\
\hline Previous cardiac surgery & 1.22 & 1.16 & 1.27 & .0001 \\
\hline Urgent admission & 1.10 & 1.08 & 1.13 & .0001 \\
\hline $\mathrm{CABG}$ & 1.14 & 1.11 & 1.16 & .0001 \\
\hline Other valve surgery & 1.20 & 1.18 & 1.23 & .0001 \\
\hline \multicolumn{5}{|l|}{$\begin{array}{l}\text { Hospital annual volume } \\
\text { of mitral valve } \\
\text { procedures }\end{array}$} \\
\hline$\leq 5^{*}$ & 1.11 & 1.06 & 1.18 & \\
\hline $6-10^{*}$ & 1.06 & 1.02 & 1.10 & .0002 \\
\hline $11-20^{*}$ & 1.02 & 0.98 & 1.05 & \\
\hline $21-40^{*}$ & 1.01 & 0.98 & 1.04 & \\
\hline \multicolumn{5}{|l|}{ Repair rate } \\
\hline First quartile*** & 1.12 & 1.08 & 1.16 & \\
\hline Second quartile** & 1.08 & 1.05 & 1.12 & .0001 \\
\hline Third quartile** & 1.07 & 1.04 & 1.10 & \\
\hline
\end{tabular}

$P V D$, Peripheral vascular disease; $C A D$, coronary artery disease; $C O P D$, chronic obstructive pulmonary disease; $M I$, myocardial infarction; $C A B G$, coronary artery bypass graft. *Versus $>40$ per year. **Versus top quartile.

hospitals performing more than 40 cases per year: 5 cases or less per year, HR 1.11 (95\% CI, 1.06-1.18); and 6 to 10 cases per year, HR 1.06 (95\% CI, 1.02-1.10). A statistically significant relationship between repair rate and longterm mortality was also noted $(P=.0001)$. Hospitals with the lowest annual repair rates had an increased likelihood of long-term mortality relative to those in the top quartile: lowest quartile, HR 1.12 (95\% CI, 1.08-1.16); second quartile, HR 1.08 (95\% CI, 1.05-1.12); third quartile, HR 1.07 (95\% CI, 1.04-1.10) (Table 4).

Although low hospital volumes were associated with long-term mortality beyond 6 months, patient characteristics were also strongly associated with survival. Patients undergoing concomitant CABG or other valve surgery (HR, 1.14; $95 \%$ CI, 1.11-1.16; and HR, 1.20 ; 95\% CI, 1.18 1.23) were also at increased risk for long-term mortality. Similarly, patients presenting with an urgent admission status were at greater risk ( $\mathrm{HR}, 1.10 ; 95 \% \mathrm{CI}, 1.08-1.13)$ (Table 4). Additional patient characteristics predictive of long-term mortality included history of COPD (HR, 1.52; 95\% CI, 1.48-1.55), renal failure (HR, 1.78; 95\% CI, 
1.72-1.83), and age 75 years or more (HR, 1.54; $95 \% \mathrm{CI}$, 1.51-1.57).

\section{DISCUSSION}

In this large, national study using the Medicare database, we examined the association between hospital annual volume of Medicare mitral procedures, mitral repair rates, and mortality. A critically important observation in this study was the relatively small number of mitral valve procedures performed in elderly patients at most US hospitals. Most of these hospitals (83.9\%) performed 10 or less mitral repairs per year in this cohort of Medicare beneficiaries with a median age of 75 years. After accounting for several patient and treatment characteristics associated with 30-day and long-term mortality, we found a significant association between hospital volume of mitral procedures and outcomes. The hospital groups with the lowest volume $(\leq 5$ and 6-10 mitral procedures per year) had substantially worse short- and long-term survival than higher-volume hospitals ( $>40$ mitral cases per year). Similarly, lower annual hospital mitral valve repair rates were also independently predictive of higher operative and long-term mortality in this Medicare population.

Our findings support and extend previous reports suggesting specific volume thresholds for hospitals wishing to perform mitral valve surgery. Bridgewater and colleagues ${ }^{5}$ recommended a minimum annual volume of 50 mitral valve repairs for hospitals performing mitral valve repair. In a previous study using data from the Nationwide Inpatient Sample (NIS) database, ${ }^{6}$ we found that less than $20 \%$ of the hospitals performed more than 50 mitral procedures per year, and only $7 \%$ of the hospitals performed more than 50 mitral repairs per year. High-volume mitral valve centers are not evenly distributed across the United States, raising concerns that volume restrictions could limit access to care unless regional referral networks are developed. Such networks would affect the elderly in particular, because those in more geographically isolated areas might have to travel hundreds of miles to undergo surgery.

The low repair rates in this cohort are disappointing. This study included all hospitals in the United States that use Medicare. Most hospitals in the United States perform a limited number of mitral valve operations, and especially mitral valve repair, on elderly patients. Although the prevalence of mitral valve disease increases with age such that by age 75 years, it affects a significant portion of the population, only $5.6 \%$ of the hospitals in our study cohort performed more than 20 mitral repairs per year. ${ }^{7}$ The reasons for these findings cannot be studied using this administrative database.

Beyond our observations of overall mitral valve procedures, we also found significant variations in the use of mitral valve repair, with greater rates of repair observed in hospitals with higher annual volumes of mitral procedures. The ability to perform mitral valve repair is considered an important quality measure in mitral valve surgery. We found that lower repair rates were independently predictive of higher operative mortality and lower longterm survival. These data bear direct relevance to the recently proposed CMS guidelines for coverage for transcatheter mitral valve repair. The proposed guidelines of at least 25 total mitral valve procedures in the previous year of which at least 10 must be mitral valve repairs, is an exceedingly low threshold that will likely allow dissemination of this technology to centers with suboptimal mitral experience and higher mortality rates. Whether patients seen at these centers are more likely to be referred to transcatheter mitral repair because of a lack of expert mitral repair surgeons remains to be seen.

The results of this investigation should be interpreted in the context of several potential limitations. The volumes of mitral procedures reported here are only reflective of mitral valve operations in the Medicare population. This offers a partial explanation for the low volumes of mitral procedures, especially mitral repairs, in this cohort. Nevertheless, because most patients in this age group have Medicare as a primary payer, this is an excellent representation of the true repair rates in the elderly, especially because the median age of this cohort was 75 years. We also examined the annual volume of mitral valve procedures across hospitals from the NIS data (all payers) for patients 65 years of age or older. The median across these hospitals ( $\mathrm{n}=891)$ was 11 (IQR, 5-23; 10th percentile, 2; 90th percentile, 42). For the MedPar data $(n=1239)$, the median annual volume was 10 (IQR, 4.5-19.5; 10th percentile, 2.4; 90th percentile, 37.3). Therefore, although without a doubt, the Medicare volumes represent a fraction of the hospital volumes of mitral procedures, these data would suggest that for patient age 65 years and older the Medicare database captures most of the mitral valve operations in the United States. In order to more accurately gauge the true level of experience level, we then looked at the NIS data to determine annual volumes of mitral procedures based on patients of all ages. The median annual volume across these hospitals $(\mathrm{n}=904)$ was 20.5 (IQR, 9.0-40.4; 10th percentile, 4; 90th percentile, 78). The correlation between annual volumes based on patients of all ages and based on patients aged 65 years or more having Medicare as the primary payer was $r=0.96$. Thus, on average, the real volume of mitral procedures (experience level) at hospitals may be almost twice that calculated from the MedPar data; however, it would seem that hospitals with a higher overall volume of mitral procedures also tend to have higher volumes of Medicare patients undergoing mitral procedures.

The greater burden of comorbidities and higher perioperative risk in the elderly would support the development of volume thresholds as a marker of quality in this population. Nevertheless, our description of low volumes of procedures in this Medicare cohort may not be a good indication of the 
quality of programs that provide substantial numbers of mitral valve procedures to younger patients. Despite this potential limitation, we did observe a strong volume-outcome relationship for the older population. An additional concern is that we relied on administrative data to assess comorbidities and could not account for the severity of various comorbidities or the cause of mitral valve disease. Given that different causes of disease, such as degenerative mitral regurgitation, can be associated with significantly higher repair rates than other causes such as endocarditis, endstage renal disease, rheumatic disease, or lupus, ${ }^{2,8-10}$ we are limited in our ability to explain the reasons why replacement rather than repair was chosen as the treatment strategy. We also did not have access to the patients' preprocedural health status, which has previously been shown to be associated with periprocedural mortality. ${ }^{11}$ Future studies that incorporate echocardiographic and intraoperative information may better address the potential selection biases between alternative treatment strategies. We were, however, able to account for some patient characteristics that are negatively associated with the performance of mitral valve repair, such as older age, urgent or emergency status, race, socioeconomic status, and female gender. ${ }^{12-15}$

The purpose of an administrative database such as Medicare is to gather billing data and therefore it does not provide as much clinical detail compared with the STS database. However, it does have the potential to capture most patients aged 65 years and older and provides data that are free of inclusion bias related to differing hospital outcomes for participating versus nonparticipating hospitals in the STS database. In addition, we cannot exclude potential unmeasured confounders associated with hospital volumes that might account for some of our observations. We cannot provide a specific volume that may be used as a cut-off to examine and compare hospital outcomes. Professional societies and health care planners will need to consider these data in the context of other economic, access to care, and health planning issues to develop rational criteria for using treatment volumes in the elderly as a potential performance measure of quality.

Although we have performed a descriptive analysis of the association between hospital volume of mitral procedures, repair rates, and outcomes in the Medicare population, we cannot make any conclusions regarding causation. Although it is plausible that higher volumes lead to improved outcomes (the learning curve), it is also possible that hospitals with improved outcomes gain volume over time (the selective referral mechanism). ${ }^{16}$

In conclusion, we found that mitral valve repair rates and mortality in the Medicare population vary by hospital annual volume of mitral procedures and that most hospitals have a limited experience in treating elderly patients with mitral valve disease. We found a significant increase in mitral repair rates and a decrease in mortality as a function of hospital annual volume of mitral procedures. After accounting for differences in hospital volume of mitral procedures, annual hospital mitral repair rates were also independently predictive of operative mortality. Future work is needed in order to consider performance measures or regional health care planning as potential vehicles for improving outcomes.

\section{Conflict of Interest Statement}

Authors have nothing to disclose with regard to commercial support.

\section{References}

1. Vassileva CM, Mishkel G, McNeely C, Boley T, Markwell S, Scaife S, et al. Long term survival of patients undergoing mitral valve repair and replacement: a longitudinal analysis of Medicare fee-for-service beneficiaries. Circulation. 2013; 127:1870-6.

2. Gammie JS, Sheng S, Griffith BP, Peterson ED, Rankin JS, O'Brien SM, et al. Trends in mitral valve surgery in the United States: results from the Society of Thoracic Surgeons Adult Cardiac Surgery Database. Ann Thorac Surg. 2009; 87:1431-7.

3. Gammie JS, O'Brien SM, Griffith BP, Ferguson TB, Peterson ED. Influence of hospital procedural volume on care process and mortality for patients undergoing elective surgery for mitral regurgitation. Circulation. 2007;115:881-7.

4. Birkmeyer JD, Siewers AE, Finlayson EV, Stukel TA, Lucas FL, Batista I, et al. Hospital volume and surgical mortality in the United States. N Engl J Med. 2002; 346:1128-37.

5. Bridgewater B, Hooper T, Munsch C, Hunter S, von Oppell U, Livesey S, et al. Mitral repair best practice: proposed standards. Heart. 2006;92:939-44.

6. Vassileva CM, Boley T, Markwell S, Hazelrigg S. Impact of hospital annual mitral procedural volume on mitral valve repair rates and mortality. J Heart Valve Dis. 2012;21:41-7.

7. Nkomo VT, Gardin JM, Skelton TN, Gottdiener JS, Scott CG, EnriquezSarano M. Burden of valvular heart diseases: a population-based study. Lancet. 2006;368:1005-11.

8. Vassileva CM, Brennan JM, Gammie JS, Sheng S, Boley T, Saha-Chaudhuri P, et al. Mitral procedure selection in patients on dialysis: does mitral repair influence outcomes? J Thorac Cardiovasc Surg. 2014;148:144-50.

9. Vassileva CM, Kwedar K, Boley T, Markwell S, Hazelrigg S. Mitral valve procedure selection in paitents with rheumatoid arthritis. J Heart Valve Dis. 2013; 22:14-9.

10. Vassileva CM, Swong MN, Boley T, Markwell S, Hazelrigg S. Influence of systemic lupus erythematosus on procedure selection and outcomes of patients undergoing isolated mitral valve surgery. J Card Surg. 2012;27:29-33.

11. Rumsfeld JS, MaWhinney S, McCarthy M Jr, Shroyer AL, VillaNueva CB, O'Brien M, et al. Health-related quality of life as a predictor of mortality following coronary artery bypass graft surgery. Participants of the Department of Veterans Affairs Cooperative Study Group on Processes, Structures, and Outcomes of Care in Cardiac Surgery. JAMA. 1999;281:1298-303.

12. Bolling SF, Li S, O’Brien SM, Brennan JM, Prager RL, Gammie JS. Predictors of mitral valve repair: clinical and surgeon factors. Ann Thorac Surg. 2010;90: 1904-11.

13. Vassileva CM, Stelle LM, Markwell S, Boley T, Hazelrigg S. Sex differences in procedure selection and outcomes of patients undergoing mitral valve surgery. Heart Surg Forum. 2011;14:E276-82.

14. Vassileva CM, Markwell S, Boley T, Hazelrigg S. Impact of race on mitral procedure selection and short-term outcomes of patients undergoing mitral valve surgery. Heart Surg Forum. 2011;14:E221-6.

15. Vassileva CM, McNeely C, Mishkel G, Boley T, Markwell S, Hazelrigg S. Gender differences in long-term survival of Medicare beneficiaries undergoing mitral valve surgery. Ann Thorac Surg. 2013;96:1367-73.

16. Barker D, Rosenthal G, Cram P. Simultaneous relationships between procedure volume and mortality: do they bias studies of mortality at specialty hospitals? Health Econ. 2011;20:505-18.

Key words: mitral valve, surgery, hospital volume, outcome research 
TABLE E1. ICD-9-CM codes used for exclusions

\begin{tabular}{|c|c|}
\hline Exclusions & ICD-9-CM codes \\
\hline Closed heart valvuloplasty & $35.00,35.01,35.02,35.03,35.04$ \\
\hline Congenital anomaly & $\begin{array}{c}35.8,35.4,35.53,35.54,35.62 \\
35.63,35.9,39.0,39.21\end{array}$ \\
\hline Heart transplant & 37.51 \\
\hline Awaiting transplant & V49.83 \\
\hline History of heart transplant & V42.1 \\
\hline $\begin{array}{l}\text { History of ventricular support } \\
\text { procedures }\end{array}$ & $\begin{array}{c}37.52,37.62,37.64,37.65,37.66 \\
37.68,39.65,39.66,97.44\end{array}$ \\
\hline $\begin{array}{l}\text { Implantation of external support } \\
\text { device }\end{array}$ & 37.41 \\
\hline $\begin{array}{l}\text { History of ventricular assist device } \\
\text { or artificial heart }\end{array}$ & V43.21, V43.22 \\
\hline Excision of ventricular aneurysm & $37.32,37.35,37.49$ \\
\hline Replacement of thoracic aorta & 38.45 \\
\hline Aortic fenestration & 39.54 \\
\hline $\begin{array}{l}\text { Concomitant carotid } \\
\text { endarterectomy }\end{array}$ & 38.12 \\
\hline Rupture of papillary muscle & 429.6 \\
\hline $\begin{array}{l}\text { Repair or replacement, unspecified } \\
\text { valve }\end{array}$ & $35.10,35.20$ \\
\hline
\end{tabular}

